\title{
Avaliação da microestrutura e da microdureza do ferro fundido cinzento
}

\section{Avaliation of microstructure and microhardness of gray cast iron}

\author{
${ }^{1}$ Leonardo de Sousa Coutinho \\ 1 Jorge João Ferreira de Souza Junior \\ ${ }^{1}$ Marco de Oliveira Vargas Francisco \\ 1 Thais Pereira dias Gusmão \\ ${ }^{2}$ Ricardo de Freitas Cabral
}

\footnotetext{
1 Discente do Mestrado Profissional em Materiais Centro Universitário de Volta Redonda - UniFOA.

2 Professor Doutor, Centro Universitário de Volta Redonda - UniFOA / Centro Universitário Geraldo di Biase - UGB.
}

\section{Resumo}

Estudos sobre ferro fundido têm sido diversamente difundidos com o passar dos anos, devido a seu baixo custo e sua alta aplicação de mercado. Este trabalho tem como objetivo principal a caracterização microestrutural e a análise da Microdureza Vickers no ferro fundido cinzento que se diferenciam pela quantidade de Carbono existente na composição química, com 2,5 e 4,0\%, e de silício, variando entre 1,0 e 3,0 . As amostras foram preparadas metalograficamente, conforme norma ASTM E 407. As análises foram realizadas, utilizando-se os seguintes equipamentos: Microscópio Óptico (MO), Microscópio Eletrônico de Varredura (MEV) e Microdurômetro. Análises em MO mostram a morfologia das amostras. Também utilizou-se o MEV para uma melhor visualização da morfologia da microestrutura. Testes de microdureza na escala Vickers foram realizados com duas cargas de indentação, 300 e 500 gf. A dureza por microindentação Vickers da amostra ficou em torno de $230 \mathrm{HV}$.

\section{Palavras-chave}

Ferro fundido cinzento; microestrutura; microdureza Vickers; grafita.

\begin{abstract}
Studies Cast Iron have been variously circulated over the years due to its low cost and its high application market. This work has as main objective the microstructural characterization and the analysis of Microhardness Vickers in gray cast iron with differing amount of carbon in the chemical composition 2.5 and $4.0 \%$ and silicon ranging between 1.0 and 3.0 . Samples were prepared metallographic as ASTM E 407. Analyzes were performed using the following equipment: Optical Microscope (OM), Scanning Electron Microscope (SEM) and Microdurometer. MO analyzes show the morphology of samples also used the SEM to better display the microstructural morphology. Microhardness on the Vickers scale tests were performed with two batches of indentation 300 to 500 gf. Hardness by Vickers microindentação sample was approximately $230 \mathrm{HV}$.
\end{abstract}

\section{Keywords}

Gray cast iron; microstructure; Vickers microhardness; graffita.

\section{Como você deve citar?}

CABRAL, Ricardo de Freitas et al. Avaliação da microestrutura e da microdureza do ferro fundido cinzento. Cadernos UniFOA, Volta Redonda, n. 28, p. 17-23, ago. 2015. 


\section{INTRODUÇÃO}

De maneira genérica os ferros fundidos são definidos como uma classe de ligas ferrosas Fe-Si-C com teores de carbono acima de $2,11 \%$. O silício é proveniente, em geral, da própria matéria-prima e fica retido no ferro durante o processo. ${ }^{[1,2]}$

Classificam-se os ferros fundidos comerciais como aqueles materiais com teores de carbono no intervalo $(3,0-4,5) \%$ de carbono (C) e com outros elementos de liga presentes. ${ }^{[1,2]}$

A formação da grafita nos ferros fundidos é regulada pela composição e pela taxa de resfriamento. Concentrações de silício (Si) maiores que, aproximadamente, 1\% promovem a grafitização (formação da grafita). Taxas de resfriamento muito baixas durante a solidificação também favorecem a formação da grafita. ${ }^{[3,4,5]}$

Os tipos mais comuns de ferros fundidos são os ferros fundidos cinzentos, nodular (ou dúctil), branco e maleável (figuras 1 e 2). ${ }^{[1]}$

Figura 1 - Classificação dos Materiais

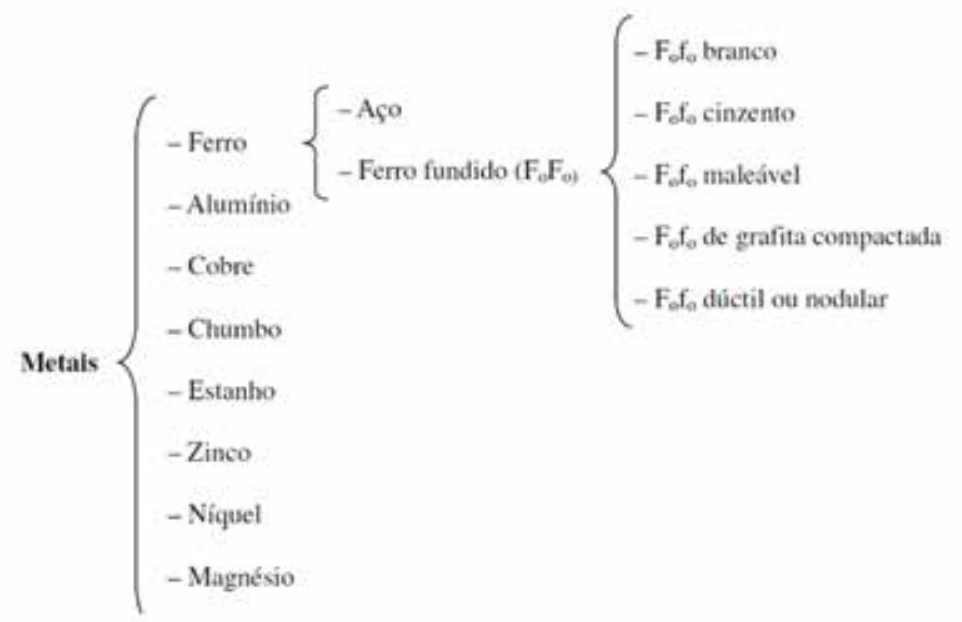

Figira 2 - Caracterização dos diferentes ferros fundidos.

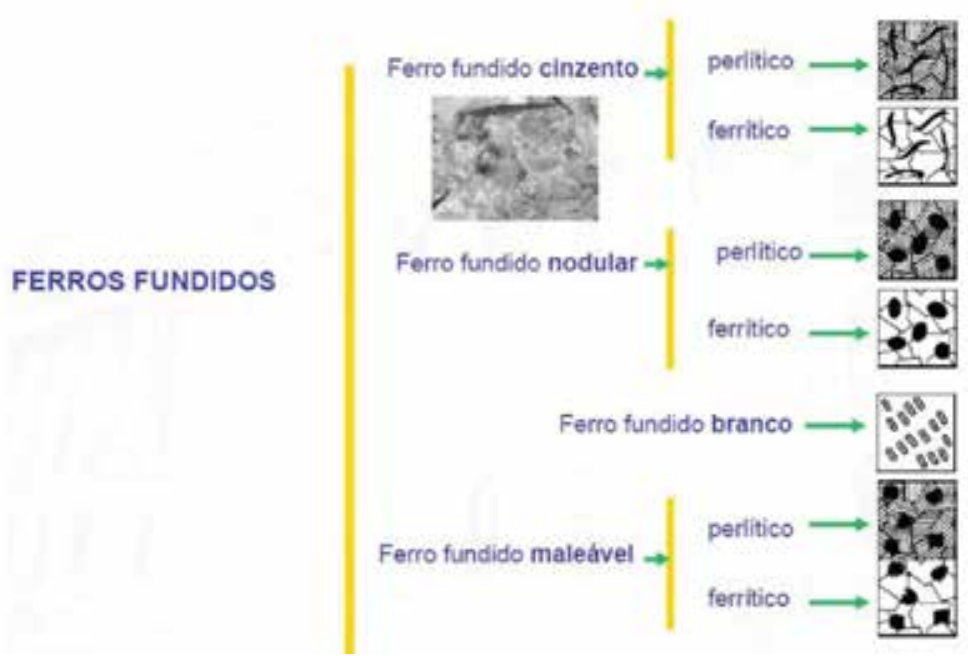


A Figura 3 (a), (b), (c) e (d) apresenta a composição do ferro fundido cinzento de acordo com o trabalho de Marmontel (2011). Nela são apresentadas as microestruturas de típica, grafita, ferrita e perlita.

Figura 3 - Composição do Ferro Fundido Cinzento: (a) Típica; (b) Grafita; (c) Ferrita; (d) Perlita

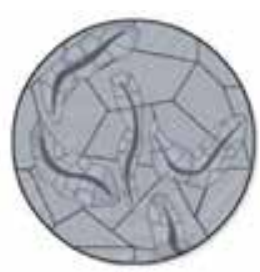

(a)

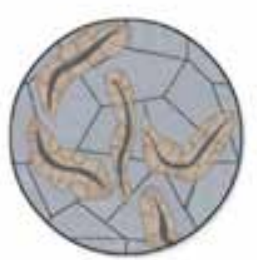

(c)

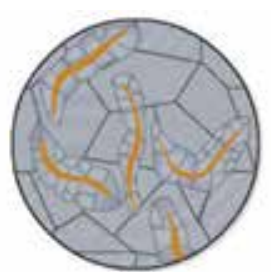

(b)

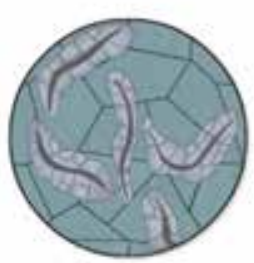

(d)

Este trabalho dará ênfase sobre o ferro fundido cinzento que é caracterizado pelos teores de carbono que variam entre 2,5 e 4,0\% e de silício, variando entre 1,0 e 3,0[1].

Este tipo de material é utilizado em larga escala pela indústria de máquinas e equipamentos, indústria automobilística, ferroviária, naval e outras. A presença de veios de grafite em sua microestrutura proporciona diversas características que tornam do ferro fundido cinzento quase que insubstituível na fabricação de carcaças de motores e bases de equipamentos.

O grafite, para matriz metálica, absorve vibrações, facilita a usinagem e confere ao ferro fundido uma melhor estabilidade dimensional. Existem diversas classes de ferro fundido cinzento, com diferentes tipos, tamanhos e quantidades de grafite, além de diferentes tipos de matriz metálica (variações nos teores de perlita e ferrita). Podem ser submetidos a tratamentos térmicos para endurecimento localizado, entretanto, normalmente são utilizados nos estados normalizado ou recozido. ${ }^{[2,3 \text { e } 4]}$

\section{MATERIAIS E MÉTODOS}

Foi utilizada uma amostra de ferro fundido Cinzento, utilizando-se uma Cortadora Metalográfica Teclago C M40, com disco abrasivo, do UniFOA. Em seguida, a amostra foi embutida à quente, utilizando-se baquelite na Embutidora Metalográfica Arotec PRE 30 Mi. Após o embutimento, a amostra foi submetida ao processo de lixamento, utilizando-se uma Politriz Lixadeira Metalográfica Arotec e lixas de carbeto de silício com oito granulometrias distintas, obedecendo a seguinte sequência: 220,360 , $400,600,800,1000,1200$ e 1500 e a um rotacional de $90^{\circ}$ para um melhor acabamento superficial do corpo de prova. Após esse processo, foi levada até o Microscópio Óptico Opton, que possui uma lente ocular de 10x e lentes objetivas de 10x, 20x e 40x para verificar o progresso do lixamento. Para melhor acabamento superficial, repetiu-se o lixamento com as lixas de 1000, 1200 e 1500. 
Após o lixamento e análise da superfície, foi realizado o polimento, utilizando uma Politriz com um feltro apropriado e alumina, com diferentes granulometrias $(1 \mu \mathrm{m}, 0,3 \mu \mathrm{m}$ e $0,05 \mu \mathrm{m})$, a fim de se obter uma superfície espelhada, ideal para realizar a última etapa do procedimento, o ataque químico. 0 reagente utilizado para atacar quimicamente a amostra foi o Nital $2 \%$. Foi imersa a amostra durante 3 segundos, em um recipiente contendo o reagente químico, para revelação das microestruturas típicas do ferro fundido cinzento.

Após o ataque químico, a amostra foi lavada e, em seguida, seca, a fim de isentá-la de qualquer impureza que pudesse dificultar a visualização da superfície atacada. Utilizou-se o Microscópio Metalográfico Invertido Opton TNM-07T-PL e um Microcomputador com o software ScopePhoto 3.0, ambos do UniFOA, para realizar a microscopia ótica nas ampliações desejadas.

Foram realizadas as seguintes caracterizações: Microdureza Vickers (HV), utilizando um Microdurômetro Time DHV 1000, cuja carga varia de 10 a 1000 gf (grama força), nas cargas de 300 e $500 \mathrm{gf}$, com um Penetrador piramidal de diamante de base quadrada, com ângulo de $136^{\circ}$ entre as faces. Foi realizada na análise por Microscopia Eletrônica de Varredura, utilizando ampliações de 200x, 500x, 800x, 1200x e 1500x para obtenção da microestrutura típica do material em questão. E, ainda, a dureza Rockwell, em um Durômetro Pantec modelo RANS-RS, do UniFOA.

Para o cálculo da dureza por microindentação Vivkers foi utilizada a Equação 1:

$$
\mathrm{HV}=\frac{1,8544 F}{d^{2}}
$$

Onde:

F é dado em Kgf (kilograma força); e

$d$ é a média das diagonais de indentação

Em seguida verificou-se a morfologia da microestrutura do corpo de prova, utilizando um Microscópio Eletrônico por Varredura (MEV) Hitachi, modelo TM3000, do UniFOA, no qual, primeiramente, foi necessário criar vácuo para não oxidar a amostra e também inserir uma lâmina de cobre para melhorar a condutividade elétrica do material.

Para obter a dureza Rockwell, foi utilizado um Durômetro Pantec, modelo RANS-RS, do UniFOA no qual se pode verificar a Dureza Rockwell, Rockwell Superficial e Brinel. Para o início de utilização do Durômetro, se fez necessário a inserção de um contra peso com a carga correspondente a análise a ser feita e também a execução de uma pré-carga para $10 \mathrm{~kg}$ de massa para apoiar o corpo de prova. 0 durômetro consiste de um penetrador de esfera de aço temperado 1/16" com 100 kgf de carga.

\section{$3 \quad$ RESULTADOS E DISCUSSÕES}

A Figura 4 (a), (b), (c) e (d) apresentam as imagens por microscopia óptica com as ampliações de 100x, 200x, 400x e 1400x, respectivamente. Como se pode observar, há presença da microestrutura típica, grafita, ferita e perlita, de acordo com a Figura 3. 
Leonardo de Sousa Coutinho / Jorge João Ferreira de Souza Junior Marco de Oliveira Vargas Francisco / Thais Pereira dias Gusmão / Ricardo de Freitas Cabral

Figura 4 - Microscopia ótica: (a) 100x; (b) 200x; (c) 400x; (d) 1400x
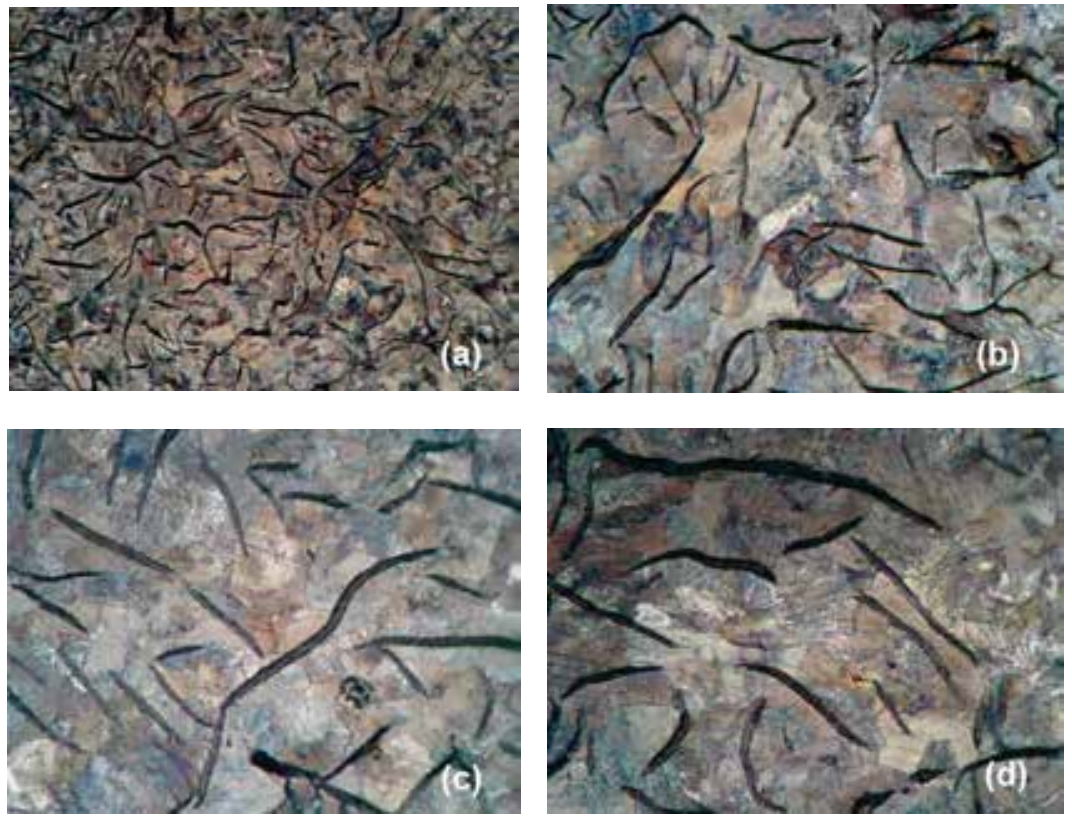

A Figura 5 apresenta os valores da dureza por microindentação Vickers nas cargas de 300 e 500 gf. Os valores para esses cargas apresentaram uma média compreendida entre 225 a $235 \mathrm{HV}$, o que denota que a microestrutura está homogênea. Esse fato é facilmente comprovado quando comparado com as imagens obtidas por MEV, nas Figuras 6 (a), (b), (c) e (d).

Figura 5 - Valores de dureza por microindentação Vickers com cargas de 300 e 500 gf do ferro fundido cinzento

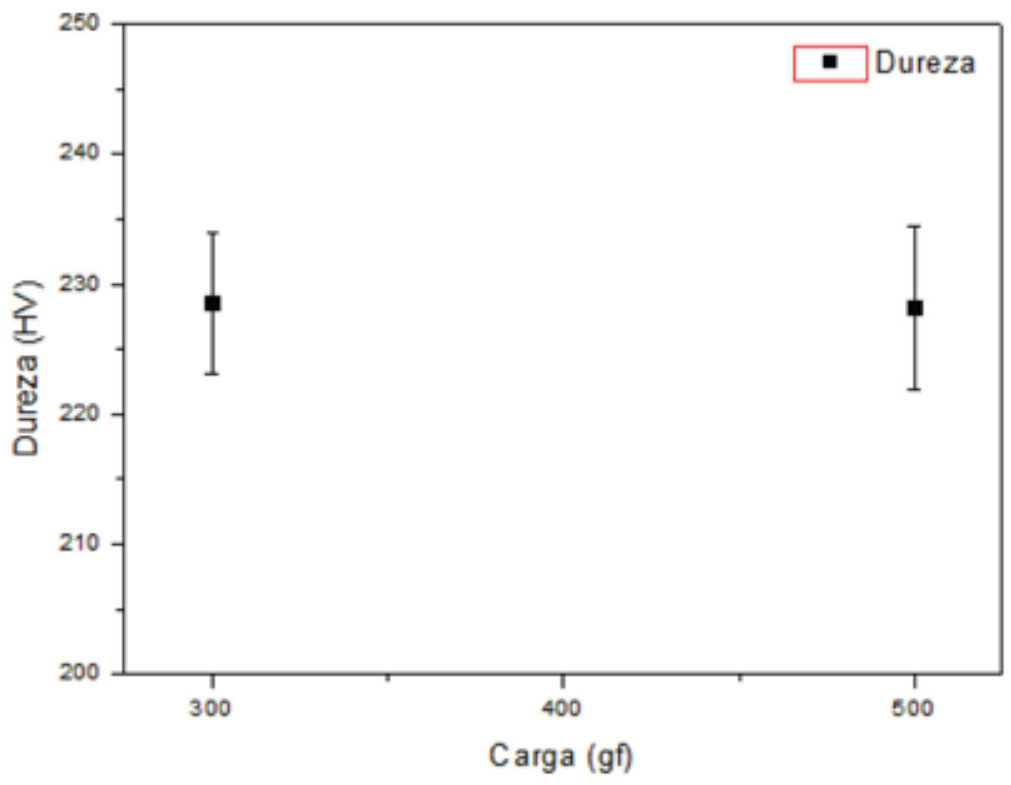


Como pode ser visto nas Figuras 6 (a), (b), (c) e (d), a morfologia apresentou os seus microconstituintes típicos de um ferro fundido cinzento, ou seja, perlita, ferrita e grafita de forma homogênea, o que corrobora as imagens vistas também por microscopia óptica do trabalho de Marmontel (2011) (Figura 3) e as imagens obtidas nesta pesquisa (Figura 4).

A microestrutura típica dos ferros fundidos cinzentos é uma matriz perlítica com veios de grafite dispersos. Sendo assim, percebe-se que as imagens da Figura 6 podem ser classificadas mediante aos tipos e distribuição dos veios de grafite, segundo aos padrões ASTM.

Figura 6 - Microscopia da amostra: (a) 200x; (b) 500x; (c) 800x; (d) 1200x
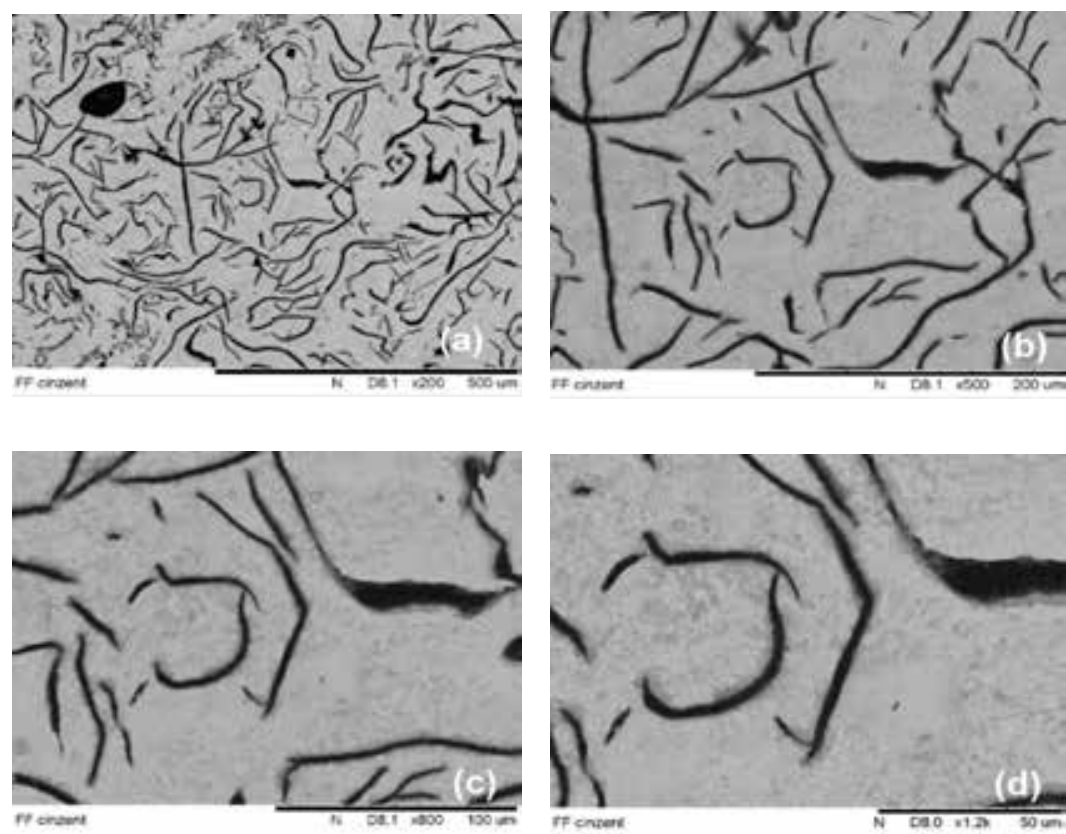

Os resultados dos ensaios de dureza Rockwell foram de 87 HRB, 89 HRB, 90 HRB e 90 HRB, com média de $89 \mathrm{HRB}$, o que está de acordo com os resultados de literatura, segundo a pesquisa de Branco (2007).

\section{CONCLUSÕES}

A amostra apresentou acabamento superficial condizente com o esperado para o ferro fundido cinzento.

A dureza por microindentação Vickers apresentou valores dentro da mesma faixa para as cargas de 300 e 500 gf, 225 HV e 235 HV.

As imagens de MEV mostraram microestruturas com as composições típicas do ferro fundido cinzendo, ferrita, perlita e grafita.

A dureza Rockwell apresentou o valor médio de 89 HRB. 
Leonardo de Sousa Coutinho / Jorge João Ferreira de Souza Junior Marco de Oliveira Vargas Francisco / Thais Pereira dias Gusmão / Ricardo de Freitas Cabral

\section{REFERÊNCIAS}

[1] BRANCO, F. K.. Influência da Microestrutura na Anisotropia de Chapas Metálicas de Diferentes Aços Estruturais. 2007. Projeto de Iniciação Científica; 2007, FEI, Centro Universitário da FEI, São Paulo, 2007.

[2] PORTAL METÁLICA (Brasil). Disponível em: <http://www.metalica.com.br/o-que-e-aco-carbono/>. Acesso em: 22 nov. 2014.

[3] MARMONTEL, C. F. F; SILVA, J. M. G. G.; OLIVEIRA, L. L.; POLIONI, M. C. Análise Metalografia de Metais. Arte e Ciência; 2011.

[4] CIMM ensino (Brasil). Disponível em: <http://www.cimm.com.br/portal/material_didatico/6560teste-da-microdureza/>. Acesso em: 22 nov. 2014.

[5] SANTOS, S. C.; MACHADO, A. R. Furação de ferro fundido cinzento com brocas de metal duro integral, 15 th Brazilian Congresso f Mechanical Engineering, Águas de Lindóia, SP, 1999. 